\title{
The Teaching Strategy of Modern Prose in Junior Middle School
}

\author{
Zilu Ye \\ School of Curriculum and Teaching Theory, Shanxi Normal University, Linfen 041000, China
}

\begin{abstract}
Modern prose plays an indispensable role in Chinese teaching in middle schools. It is an elegant and natural language which has sincere and profound emotions. Its language has a profound influence on students' aesthetic ability, emotional attitudes and values. However, in contemporary prose teaching, the beauty and cultural connotation of prose is replaced by classroom practice of repeated exercises and exploration activities. Teachers held utilitarianism attitude to teach prose and to train students from the perspective of college entrance examinations, all of which had led to a dilemma where the aesthetic factors of prose did not play a main role in teachers' teaching and students' study. Therefore, on the basis of modern prose teaching practice, this article explores the humanistic, high-efficient and scientific implementation strategies in Chinese teaching to cultivate junior high school students' language skills, so that they can be fully developed.
\end{abstract}

Index Terms - modern prose, language teaching, aesthetic consciousness

\section{The Status of Modern Prose Teaching in Junior Middle School}

After analyzing the literature and personal internship activities, the author discovered that there are some shortcomings in the modern prose teaching. Under the environment of examination and utilitarian reading, modern prose teaching has been trapped in a deadlock. There are many problems in terms of teaching philosophy, teaching methods and students' learning attitude. The following is a summary of the current status of contemporary prose teaching in junior high school on the basis of the author's study on contemporary prose teaching:

A. Classroom Teaching Activities Are Complex and Diverse, Affecting the Integrity of Students' Experience of Aesthetic Sense of Language

As a basic course, Chinese language classes play an important role in the improvement of students' literacy, comprehensive qualities, and practical language proficiency. Prose is an important part of Chinese aesthetic language teaching because of its stylistic characteristics of aesthetic language and readability. We hope to cultivate students' aesthetic sense of language through prose teaching and improve students' expression. However, some problems have arisen in the current prose teaching classes. We know that an active language class does require a lot of teaching activities, such as: reasonably distributed group discussions, classroom presentations, and rich extracurricular knowledge development. However, some teachers nowadays have a tendency to deviate from the theme, thinking that in order to mobilize students' enthusiasm, they must organize a variety of classroom teaching activities so that most of the time of a lesson is wasted in the organization of teaching activities. What is in students' mind is only one question after another or some classroom tasks, so that forgetting their own initial experience of prose appreciation, or the student's own aesthetic experience of language has been torn apart by various questions and tasks.

\section{B. Students' Main Position Is Neglected in the Classroom of Prose Language Teaching}

As instructors of classroom teaching, each question and answer that the teachers make will have an impact on the classroom process. Teachers and students are subjective in front of the text, but they will have a totally different aesthetic experience of language. However, the author found that in the prose class, the teacher over-interpreted the text in the classroom teaching and replaced his own subjective experience with the student's experience. For example, some teachers would say in class teaching: "I thinks this article is very beautiful, especially the first few natural passages." "This article has written three parts, which are...", "I liked this article very much. The Chinese protagonist said this sentence because...". These statements all contain certain limitations. Most of which are teachers' interpretation and experience of the text, and the students in the classroom will not consciously adopt under these conditions set by the teacher, thus affecting students' language aesthetic experience. Students as the subjects of language appreciation, they have their own unique aesthetic experience for the works, and teachers should not impose their own understandings and opinions on students. We advocate that the teacher's leading role and students'main role, in particular, teachers should attach importance to the student's dominant position.

\section{In the Classroom Teaching, The Aesthetic Methods and Teaching Modes Are Single and Lack of Innovation}

Prose has flexible and diverse sentence patterns, fluctuating article structure and rich aesthetic elements. Through different aesthetic methods, we can feel the "beauty" of prose to the greatest extent. However, at present, most of aesthetic methods and teaching models are single. First, in terms of aesthetic methods, teachers use the single teaching 
method "Reading Aloud" in the process of prose interpretation, but students not only cannot feel the linguistic beauty of prose but become annoyed in the process of article reading. Teachers should recognize that reading is just a method of prose teaching, one lesson should not be composed of only one aesthetic method, and different aesthetic methods should be used flexibly to stimulate students' interest in learning. Second, in terms of teaching modes, most of teachers' classrooms are stereotyped mode, regardless of the style of writing, all of the classrooms are composed of the same procedure, like the background of the author, dividing the structure of the article, and summarizing the themes of the topic. In the long run, students are not interested in learning, teachers are not interested in teaching, and classroom teaching efficiency is getting lower and lower. In this mode, students are more and more dependent on the teacher's analysis and eventually lose their imagination and creativity. The students even did not feel the slightest sense of beauty in the prose. What they learned was only some abstract empty concepts.

\section{Utilitarianism and Practicality of Aesthetic Attitude in Prose Teaching Class}

Although the current new curriculum reform and new curriculum standards advocate that we should not using score as the sole criterion for measuring student quality, in the face of the pressure of higher school entrance examination, a single evaluation of teachers' teaching ability and parents For children's academic achievement expectations, exam-oriented education is still a reality that cannot be completely changed at the moment. Students take utilitarian attitude to learn and teachers hold utilitarian attitude to teach, teaching content follows the content of the exam. The classroom is full of so-called exam highlights and tips. In the prose teaching class, it is shown that the teacher does not lead the students to appreciate the beauty of the text itself in the teaching process, but uses a lot of time and energy to explain the techniques and methods of prose reading to the students, or just recitations of the text. On the surface, the student's academic performance is improved, but in the long run, it has affected the improvement of students' comprehensive ability, which is contrary to the idea of the new curriculum standard and quality education. In order to make students perform well in the exam, teachers will deliberately emphasize some of the exam highlights in the classroom teaching process. In order to achieve good results, students will focus on the teacher's emphasis. So we must realize that this kind of utilitarian teaching and attitude towards prose language teaching are extremely unfavorable for the overall appreciation of the text and the improvement of the comprehensive ability of students.

\section{The Characteristics of Modern Prose and the Theory of Prose Appreciation}

Modern prose has strong characteristics and is a proof of the ideological liberation and individuality. It often uses the author's thoughts and feelings to pulse the changes in the story of the literary works. It shows a very strong interest, literariness, artistry, and can show the creativity of life in literature and art, which is helpful for the development of students' language skills in junior high school.

\section{A. Language Features of Modern Prose}

Modern prose is an important cognitive target for junior middle school students to carry out text reading, information acquisition, language practice and ability development. It provides a powerful educational force for junior high school students' language cognition, emotional experience and ideological promotion.

1. Modern prose featured with beautiful words and elegant artistic conception

In the prose teaching class in junior high school, the language in the textbook is very beautiful and profoundly capable of creating a poetic artistic conception. It can have the same strong expression and appeal as the poetry, and can bring junior high school students into the beautiful world. Therefore, some people say that beautiful prose language is like words and phrases, throwing vocal songs with poetry, and can quietly impress junior students' hearts, realize emotional resonance and sympathetic resonance in subtle emotions, and educate junior high school students in the process of giving junior high school students a high-quality aesthetic experience. Exquisite prose works bring literary nourishment and artistic influence to the development of language ability for junior high school students. They help junior high school students develop their language skills through high-quality language products, and guide junior high school students to learn in imitation and improve in learning.

2. Modern prose has the characteristics of fast rhythm and distinct emotion

With the liberation of thought and human nature, modern prose also showed a strong "humanism", language and emotional outpouring of personalization are increasingly obvious, thus creating a series of excellent emotional rhythm and lively, distinct literary works, the author expressed personal experience of love and hate and emotional social life in life. Among them, the most expressive language, thought force, fighting force and impact force of literary works is the works of Maxim Gorky <<Song of the Stormy Petrel >>, Maxim Gorky unfortunate bitter language strongly urging the revolutionary forces before the storm, highly praised by petrel as the representative of the revolutionary heroic image, reveals the great revolutionary fearless spirit and fighting spirit of optimism. Junior high school students can obtain the expression of language emotional color in the one lesson of $<<$ Song of the Stormy Petrel $>>$, which is helpful for junior middle school students to control the language.

\section{B. Theory of Modern Prose Appreciation}

1. Consistency of creative ideas and cultural needs 
The literary value of prose works depends on the author's creative thinking and the reader's literary preferences and appreciation. The creative activities of literary works have gradually changed from being sentimental, casual and creative to the creation of art directed at a certain audience. Therefore, modern prose can be easily recognized and loved by readers, and it also greatly enhances the social influence and literary value of literary works. The writing ideas and the cultural consumption demands of the masses are often intrinsically linked and consistent. They can effectively satisfy the people's emotional needs and cultural consumption demands, and show directness. Writers' proses generally shape and improve the characters by portraying the voice of the objects of creation, acting for the world and ideology. They try to present the most vivid and influential aspects of the characters to junior high school students. How to enlighten junior high school students to portray their characters and how to behave as a junior high school student. Therefore, writing prose is often the task of inspiring the mind, enlightening the people, and advocating the style of the times. Writing prose focuses on shaping the characters' image, while narrative prose tells about a touching or thought-provoking story with literary language. The author or junior high school student remembers those stories which cannot be forgotten.

2. The extension and expansion of the value of literature and art

The extension of the connotation of prose works and the artfulness are the direct expression of its literary and artistic values. In the prose language, the author often "goes out of mystery," and reserves a "thought treasure" which worthy of consideration and deep thinking for readers. It can effectively stimulate the readers' interest and the desire to explore, thus inspiring readers' motivation and making reading become a kind of self-consciousness and active consciousness, it is very helpful for readers to understand the learning of cognition and language development. The extension and expansion of literary and artistic values are mainly manifested in the visual and imaginative aspects of prose language, and have a great space for exploration. The writing essay, as the name suggests, is a literary genre that focuses on the beautiful scenery and provides the feelings of beauty for junior high school students. In the eyes of the author, all scenes have language, life, soul, and thought. They are able to exchange information and mood with the author. They are alive, independent individuals.

The linguistic features of the writing prose are very prominent. The most important feature is that there are many uses of figures of speech, which can create a beautiful, graceful, elegant and fresh natural scenery and humanistic atmosphere. The figures of speech is a magic wand that makes every flower, grass, stone and wood alive and moves, it can give life to all landscapes. Therefore, the verbal prose is often vivid, chic, profound and implicit with the help of the uses of figures of speech.

\section{The Enlightenment of Modern Prose Appreciation Theory to Junior Middle School Prose Language TEACHING}

The theory of modern prose appreciation emphasizes humanistic thinking and can effectively inspire language teaching, which to take junior high school students' physical and mental development and cognitive rules as the starting point. It is targeted to carry out a series of humanization, subjectivization, interaction, exploration and efficiency. The classroom activities reflect the truth of life.

\section{A. The Enlightenment of the Theory of Modern Prose Appreciation to the Teaching Process}

We have always stressed that students must actively study, but they do not understand what is "active"? What is the student's autonomous learning? From the author's point of view, "active" and "autonomous" are not simply refers to that the students actively write their assignments or they actively complete the teacher's extracurricular reading tasks. Because in this process, the students are still mechanically completing the tasks assigned by the teacher, their own thinking is always led by the task. In fact, the so-called "self-reliance" and "proactive" should be that students voluntarily want to read a book and voluntarily want to write a paragraph. His thoughts naturally come from his own heart. Therefore, "the surfacial initiative" is still "passive", we must pursue the real "active" in the teaching process. What we need to do in modern prose teaching is to respect the aesthetic subjective status of students in the classroom, guide students to initiate dialogues with the text, and enable students to appreciate the beauty of language in prose.

In the actual teaching process, teachers over-interpret the text and ignore the problem of students' aesthetic experience, which causes some students just to move on the surface, the classroom atmosphere seems to be active, but in fact it limits the students' thinking. We must recognize the guiding role of teachers in the classroom, but we must also recognize the main position of students. In the teaching process, teachers need to guide students to delve into the texts. They need to guide them to appreciate both the "inside" and the "outside" while enjoying the prose, so that students can comprehend the dialogue with the text. What they have learned is their understanding of the text, not the textual analysis of teachers' empty dogma. What students need to do is to actively put their own emotions and attention into prose and experience the aesthetic pleasure and reading pleasure which brought to them in the process of prose reading.

\section{B. The Enlightenment of Modern Prose Appreciation Theory to Teaching Methods}

The main way to realize the rich aesthetic elements in prose is to read, especially in aesthetic Reading. For example, Yingchao Yu teacher explains the <<purple wisteria waterfall>> this article mainly adopts the method of aesthetic Reading. He divided the classroom into two parts: the text aesthetic Reading and the text careful reading. 
The first stage is textual aesthetic reading. We begin by analyzing Yu’s classroom instruction: “今天咱们学习一篇美 文, 一篇写花的美文, 同时也是写感悟的美文。美文呢, 是要美读的, 今天咱们这节课就叫“美文品读课”。下面 咱们进入第一个学习环节——感受美。感受美, 首先要美读。读三次, 第一次是自由地大声地比较快地朗读, 感受文章的内容。好, 我们开始自读课文, 出声地阅读。”From the guide we found that Yu's instruction does not have a beautiful and gorgeous language. It simply directly emphasizes the teaching objectives and focus of the article. It also enables students to enter text directly from the beginning, avoiding interference from irrelevant information. And Ms. Yu divides the beauty of prose into three parts - feeling beauty, discovering beauty, and admiring beauty. This is exactly the three links of aesthetic activities. He really combines prose and aesthetic teaching together. In the process of student reading, Yu used different reading methods. The first is the student's free reading. This is the first time the student has contacted the text. The teacher did not arrange any teaching tasks. It was only for the students to understand the text from their own hearts and retained the students' first intuitive experience of the text. The second is that the teacher guides the students as a host to read aloud. During the guidance process, teachers explicitly conveyed the emotional tone of each paragraph to the students, enabling them to follow their prose to constantly adjust their emotional state and feel the emotions of the articles together. . The third type is free reading. Students choose their favorite or the most touching text to perform reading. This reading method can enable teachers to quickly grasp the students' aesthetic status and enhance the ability of comprehending articles.

Then, Yu entered the careful reading stage of the text. In order to let the students to find out what they thought was a beautiful sentence and to explain where it was beautiful. The teacher Yu directly provided the students with a beginning sentence: “我读了这个地方, 觉得它美, 美在…..”, so this way of teaching guide students to keep them away from the fixed teaching mode and respect students' personalized interpretation of texts. After the students spoke enthusiastically, Ms. Yu summed up the "beauty" in this article into several parts: beauty, beauty, and beauty. In addition, teacher Yu also summarized the writing rules of this article - from the beauty of writing flowers to the beauty of writing emotions to the beauty of conception. Based on this, the characteristics of the writing of this article are drawn: lyricism and compassion. $\mathrm{Ms}$. Yu is not limited to the in-class knowledge. He also leads the students to supplement extra-curricular knowledge and guides students in learning how to read such articles.

In the above article, teacher Yu used teaching method of aesthetic perception throughout the entire class. Because of the different methods of reading each time, students did not feel boring to read in this process. Instead, they profoundly realized the beauty of the article in the course of reading it over and over again. The prose of "Wisteria Daucus Falls" has linguistical beauty, emotional beauty and philosophical beauty. Mr. Lu Shuxiang (1987) once said: "The primary task of Chinese language teaching is to cultivate students' language ability in all aspects. If there is no reading, how can it be exported?"(P.158) Prose is an aesthetic essay. There are rich aesthetic elements in contemporary prose. This kind of beauty is vividly displayed, which can guide students into the text and have open dialogues with the text, so that they understand the text of the subject and emotion. Therefore, in modern prose teaching, we can make students feel the beauty of prose by reading and appreciating. The ancients also said that "the book is read a hundred times and its meaning is self-satisfied." But in the actual teaching process, we must pay attention to the same flexible use of different reading methods as Yu Yingchao's teacher in the course of class, such as: read aloud, recitation, aesthetic perception, Silent reading and so on. Attention should be paid to observing some emotional changes in the students' reading process. Do not make students feel bored during the reading of articles.

\section{The Enlightenment of Modern Prose Appreciation Theory to Teaching Atmosphere}

Modern prose with the characteristics of "dispersive and diversified style" which require teachers to take the initiative to "untie" junior high school students, and to restore their original free, and open cognitive qualities. The self-study displays life's aura and truly shows the bottommost emotional experience and ideology of human nature. Therefore, teachers should open up the teaching atmosphere, guide junior high school students to fly their imagination wings, and happily invite the excellent literary palace created in prose, maximize the closeness of the creative background of literary works, and fully absorb the spiritual food implied in literary works. Cultural nourishment promotes the development of junior high school students' language ability and healthy growth.

\section{The Enlightenment of Modern Prose Appreciation Theory to Teaching Goals}

Prose occupies half of the Chinese language teaching materials in middle schools, which is also an important part of Chinese teaching in middle schools. Moreover, the reading and appreciation questions in Chinese proses are still occupying a certain percentage of scores. Some teachers take utilitarian aesthetic attitudes in the context of exams so that they always organize classes from the completion of teaching tasks and the improvements of students' test scores. They ignore individual differences between students and their interpretation of texts. Students are always led by teachers so that lost their space to interpret the text and exert their imagination. Zhu Guangqian (2015) has talked about the distance between art and real life in his book, he sums it up as "the fan of the authorities and the spectators"(P.15). He believes that "if we want to see the beauty of things, we must jump from the practical world and appreciate their own beauty in a spirit of 'doing nothing.'" He said, "The skills of artists and aestheticians are in them." You can jump out of the trap of interest and only conscientiously watch the image of the thing itself. They know that there is a proper distance between the things of the United States and the real life."(Zhu Guangqian, 2015, 17). So if teaching is to 
achieve an aesthetic interpretation of the article, it must be set aside the idea of pragmatism, such as test-taking concepts and answering techniques, and begins with appreciation of the text itself and the beauty of the article. In this way, students can have the most genuine emotional resonance with the texts in the teaching process. The actual practice of prose teaching in middle School can be expressed as follows: First, teachers must learn to respect the prose style and the text in the classroom teaching process to maintain a proper distance, do not over-interpret the text, so that it can be "inside it" It can be "outside of it." Second, we must fully respect the subjective status and aesthetic experience of students and encourage them to interpret the text in a personalized way. Third, both teachers and students should abandon the idea of utilitarianism and pragmatism when dealing with texts and simply interpreting texts from the aesthetic point of view.

\section{CONCLUSION}

The ultimate goal of prose language teaching is to cultivate students' ability to experience beauty, appreciate beauty, discover beauty and create beauty in the classroom teaching process. In this process, not only the teaching of knowledge, the improvement of teaching content, but also the cultivation of students' language ability should be emphasized. The shaping of personality makes them gradually form their own language perception ability and correct emotional attitudes and values. Teachers should adopt correct teaching methods in the teaching process to make students realize that the articles have more in-depth content than the basic words, the structure of the chapters, and the meaning of paragraphs. At the same time, teachers should learn to understand the new curriculum standards and establish a correct aesthetic attitude, based on a reasonable interpretation of the text to avoid over-interpretation. Students should learn to concentrate themselves on the text of the prose and form their own personalized interpretation of the language during the process of reading the articles. This article is mainly designed to observe the problem of some prose teaching in the process of Chinese classroom teaching. It is guided by modern prose appreciation theory, and on this basis, some improved teaching strategies are proposed. The author is well aware of the truth of the knowledge practice, and will continue to explore in the future teaching practice. Along with polishing his article, he will gather experience and further propose a new language teaching strategy.

\section{REFERENCES}

[1] Kong Ruisheng. (2009). Elementary Introduction of Prose Aesthetic Education in Middle School Chinese Teaching: Modern Language and Teaching Research, 2, 101-102.

[2] Li Fudong, Jiang Yuanfu \& Zhang Xijiu. (2003). The Fourth Chapter of Prose Appreciation: Language Teaching Communication, Z2, 40-60.

[3] Li Hailin \&Wang Rongsheng. (2011). Prose Teaching Should Return from "Outside" to "Inside": Chinese Teaching in Middle Schools, 2,18-26.

[4] Li Jinglong. (2008). Elementary Introduction to The Success of Junior High School Prose Teaching under The New Curriculum Standard: Education, 7, 36-36.

[5] Li Ping. (1999). Play The Function of Chinese Aesthetic Education to Improve Students' Quality: Tianjin Education, Z1, 65-66.

[6] Lu Shuxiang. (1987). Chinese Language Collection. Jinan: Shandong Education Press, 158.

[7] Sun Shaozhen. (2008). Prose from The Aesthetic, Aesthetic (sub to comment on ugliness) History of Contemporary Prose Theory and Logic in The Unified: Contemporary Writers Trial Intellectual, 1, 81-96.

[8] Zhu Guangqian. (2015). Talking About The Beauty. Nanjing: Jiangsu People's Publishing House, 15.

[9] Zeng Fanren. (1999). Aesthetic Aducation of Modern Significance: Journal of Shandong University (Philosophy and Social Sciences Edition), 3, 27-31.

Zilu Ye was born in Taiyuan, Shanxi in 1993. She received her bachelor's degree in Chinese Language and Literature from Taiyuan Normal University, Shanxi in 2016.

She is currently a postgraduate for her master's degree and majoring in Curriculum and Teaching Theory in Shanxi Normal University. Her research interests included language teaching and teaching theory. 